\title{
Bonding, Electron Densities and Vibration Frequencies of [3]-, [4]-, [5]- and [6]-Radialenes; a B3LYP Density Functional Study
}

\author{
Muthana Shanshal and Rehab M. Kubba \\ Department of Chemistry, College of Science, University of Baghdad, Jadiriya, Baghdad, Iraq \\ Reprint requests to Prof. M. S.; E-mail: mshanshal2003@yahoo.com
}

Z. Naturforsch. 61a, 95 - 98 (2006); received October 26, 2005

B3LYP density functional treatment is reported for the [3]- to [6]-radialene. For the first two molecules the corresponding $D_{n h}$ symmetry resulted from the treatment. For the [5]-radialene, the completely planar $D_{5 h}$ structure was found energetically a non-minimal configuration showing two imaginary vibrations. An almost planar $C_{1}$ structure of [5]-radialene emerged as the stable species. As for [6]-radialene, the planar $D_{6 h}$ structure proved to be a non-minimal structure too, showing three imaginary vibrations. The $D_{3 d}$ chair form was most stable, followed by a twisted boat form of the molecule. The chair form of [6]-radialene was more stable than the twist boat form by $0.9 \mathrm{kcal} / \mathrm{mol}$. Variation of the bond lengths, of $\mathrm{A}_{1 \mathrm{~g}}\left(v_{\mathrm{CC}}\right.$ and $\left.v_{\mathrm{CH}}\right)$ vibration frequencies as well as of the total $\left(\rho^{\text {tot }}\right)$ and $\sigma\left(\rho^{\sigma}\right)$ electron densities for the four molecules, compared with those of ethylene, is discussed. To explain the results, a bonding model for the radialene rings is suggested, which assumes an sp hybridization of the ring atoms in [3]- and [4]-radialenes going over to $\mathrm{sp}^{2}$ hybridization in [5]- and [6]-radialenes.

Key words: Radialene; Frequency; Geometry; Density.

\section{Introduction}

Radialenes are organic molecules of considerable chemical interest due to their high reactivity, molecular strain and cross conjugation of their $\pi$-bonds, which might enable their technical applications in the future [1]. It was shown in [2] that the C-C chemical bonding in [3]-radialene may be described properly in terms of a "modified Förster-Walsh" model [3-6], in which the ring carbon atoms possess an sp hybridization. Both the calculated geometry and vibration frequencies are consistent with such a model. Due to the formerly shown similarity of the chemical bonding in 3 - and 4-membered rings [6], similar sp hybridized carbon atoms of [4]-radialene are expected.

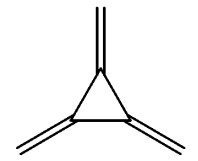

[3]-Radialene

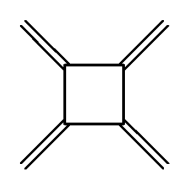

[4]-Radialene
Going to [5]- and [6]-radialenes, the C-C-C bond angles diverge towards $120^{\circ}[7,8]$, and a gradual transition to $\mathrm{sp}^{2}$ hybridization is expected.

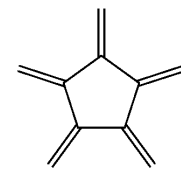

[5]-Radialene

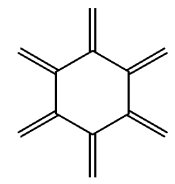

[6]-Radialene
The suggested bonding model for radialenes should allow proper explanation of their different properties, as they result from measurements and quantum mechanical treatments. In the following we report density functional, B3LYP, calculation results for [3]- to [6]radialene and an attempt to understand them in the light of the suggested model.

\section{Results and Discussion}

Fully optimized geometries of the radialenes were obtained applying the B3LYP [9] method with the 6-311G basis [10]. For [6]-radialene, three possible structures were considered: the chair, twist boat and planar conformation. The calculations showed that both the chair and twist boat conformation form stable minima at the energy surface of the molecule. The planar $\left(D_{6 h}\right)$ structure is an unstable structure showing three imaginary vibrations; $\mathrm{B}_{2 \mathrm{~g}}\left(-118.7 \mathrm{~cm}^{-1}\right)$ and a 
Table 1. B3LYP calculated bond distances in [3]- to [6]-radialene and ethylene, compared with the corresponding experimental values.

\begin{tabular}{lccccc}
\hline & [3]-Radialene & [4]-Radialene & [5]-Radialene & [6]-Radialene (chair form) & Ethylene \\
\hline $\mathrm{C}=\mathrm{C}$ & $1.332(1.343)[12]$ & $1.332(1.326)[13]$ & 1.342 & $1.343(1.337)[14]$ & $1.331(1.337)[11]$ \\
$\mathrm{C}-\mathrm{C}$ & $1.454(1.451)[12]$ & $1.488(1.484)[12]$ & 1.493 & $1.493(1.495)[14]$ & \\
\hline
\end{tabular}

Table 2. B3LYP calculated vibration frequencies of $\mathrm{A}_{1 \mathrm{~g}}\left(v_{\mathrm{C}=\mathrm{C}}, v_{\mathrm{C}-\mathrm{C}}\right.$ and $\left.v_{\mathrm{C}-\mathrm{H}}\right)$ for [3]- to [6]-radialene and ethylene.

\begin{tabular}{lrrrrrr}
\hline & [3]-Radialene & [4]-Radialene & [5]-Radialene & [6]-Radialene (chair form) & [6]-Radialene (twist boat form) & Ethylene \\
\hline$v_{\mathrm{C}=\mathrm{C}}$ & $1854(1800)[15]$ & $1774(1681)[16]$ & $1685-$ & $1649(1650)[17]$ & 1651 & $1722(1666)[18]$ \\
$v_{\mathrm{C}-\mathrm{C}}$ & $774(779)[15]$ & $706(683)[16]$ & $631-$ & $574-$ & 579 & - \\
$v_{\mathrm{C}-\mathrm{H}}$ & $2988(3000)[15]$ & $3065(2988)[16]$ & $3147-$ & $3142-$ & 3149 & $3117(3083)[18]$ \\
\hline
\end{tabular}
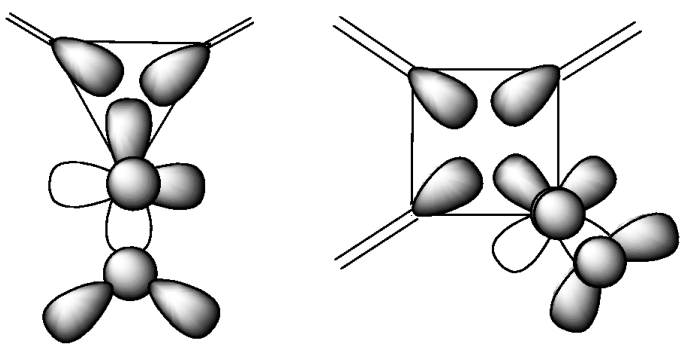

Fig. 1. Suggested sp hybridization of the ring $\mathrm{C}$ atoms in [3]and [4]-radialenes.

degenerate $\mathrm{E}_{2 \mathrm{u}}\left(-86 \mathrm{~cm}^{-1}\right)$. The stability of the chair over the twist boat conformation corresponds to an energy difference of $0.9 \mathrm{kcal} / \mathrm{mol}$. As for [5]-radialene, two conformations were considered: planar $\left(D_{5 h}\right)$ and a twist planar conformation of $C_{1}$ symmetry. The density functional treatment showed that the planar $D_{5 h}$ structure is energetically non-stable with two imaginary vibrations, a degenerate $\mathrm{E}_{2}$ " $\left(-20.39 \mathrm{~cm}^{-1}\right)$. The stable twist form is almost planar with one carbon atom tilted out of the plane formed by its three neighbored ring atoms by $\pm 3-5^{\circ}$. The calculated $\mathrm{C}=\mathrm{C}$ and $\mathrm{C}-\mathrm{C}$ bond distances of the four radialenes are listed in Table 1 .

It is seen that all the external $\mathrm{C}=\mathrm{C}$ bonds show bond lengths that are approximately equivalent to that of ethylene. A significant change is noticed on going to [5]- and [6]-radialenes. Much more obvious is the change in the ring $\mathrm{C}-\mathrm{C}$ bond distances, which vary from $1.454 \AA$ ([3]-radialene) to $1.493 \AA$ ([6]radialene). The change resembles a transition from the cyclic bond formation caused by the overlap of the Förster-Walsh orbitals in the [3]- and [4]-radialenes (Fig. 1) to the normal $\pi$-bonding caused by the olefinic overlap of the carbon $\mathrm{p}_{\mathrm{z}}$ orbitals in the [5]- and [6]radialenes.

Much more significant is the change in the $\mathrm{A}_{1 \mathrm{~g}}$ $\left(v_{\mathrm{C}=\mathrm{C}}, v_{\mathrm{C}-\mathrm{C}}\right.$ and $\left.v_{\mathrm{C}-\mathrm{H}}\right)$ stretching frequencies of the radialenes, listed in Table 2 .

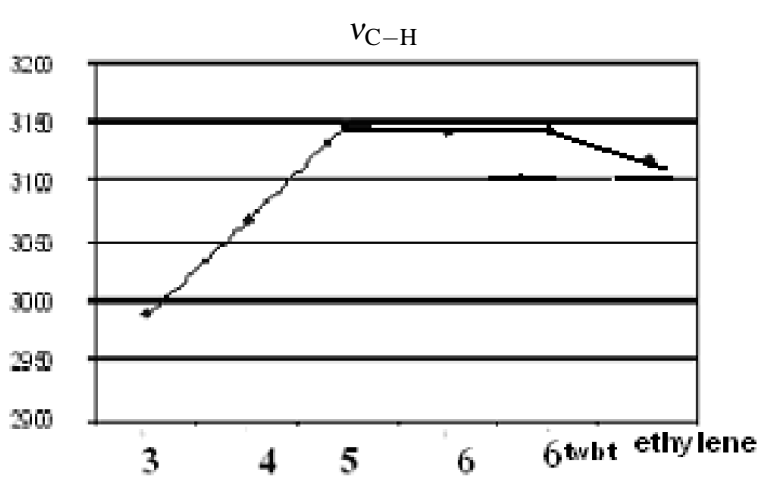

Fig. 2. Variation of $A_{1 \mathrm{~g}}\left(v_{\mathrm{C}-\mathrm{H}}\right)\left(\mathrm{cm}^{-1}\right)$ of radialenes as function of the ring number.

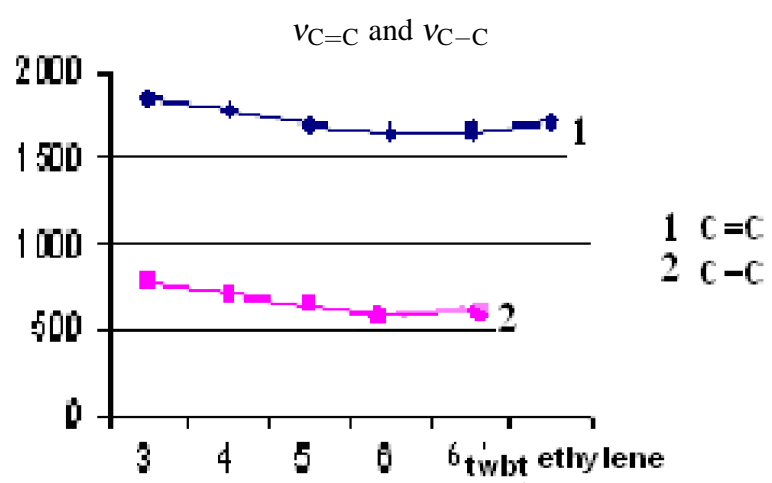

Fig. 3. Variation of $\mathrm{A}_{1 \mathrm{~g}}\left(v_{\mathrm{C}=\mathrm{C}}\right)\left(\mathrm{cm}^{-1}\right)$ and $\mathrm{A}_{1 \mathrm{~g}}\left(v_{\mathrm{C}-\mathrm{C}}\right)$ $\left(\mathrm{cm}^{-1}\right)$ of radialenes as function of the ring number.

Figures 2 and 3 show the variation for the three types of vibration frequencies due to the change of radialene ring size.

The values of both $\mathrm{CC}$ frequencies decrease on going from [3]- to [6]-radialene. The change runs parallel to the decrease in the 2 s orbitals' participation in the chemical bonding of the ring atoms, in agreement with our assumption of hybridization shift from $\mathrm{sp}$ to $\mathrm{sp}^{2}$. For both frequencies the biggest change is found at the transition from [4]- to [5]-radialene, $90 \mathrm{~cm}^{-1}\left(\Delta v_{\mathrm{C}=\mathrm{C}}\right)$ 
Table 3. Calculated total electron density $\rho^{\text {tot }}$ and $\sigma$ electron density values $\rho^{\sigma}$ for the ring and the external carbon atoms as well as the electron density values at the $\mathrm{H}$ atoms $\rho^{\mathrm{H}}$ of [3]- to [6]-radialene.

\begin{tabular}{lcccccc}
\hline & {$[3]-R a d i a l e n e$} & {$[4]-R a d i a l e n$} & {$[5]-R a d i a l e n e$} & [6]-Radialene (chair form) & [6]-Radialene (twist boat form) & Ethylene \\
\hline $\mathrm{C}_{\text {ring }} \rho^{\text {tot }}$ & 6.069 & 6.100 & 6.027 & 6.014 & 6.027 & 6.313 \\
$\mathrm{C}_{\text {ring }} \rho^{\sigma}$ & 5.084 & 5.132 & 5.041 & - & 6.110 & 5.332 \\
$\mathrm{C}_{\text {ext }} \rho^{\text {tot }}$ & 6.268 & 6.228 & 6.290 & 6.306 & - & 5.332 \\
$\mathrm{C}_{\mathrm{ext}} \rho^{\sigma}$ & 5.253 & 5.212 & 5.281 & - & 0.838 & 0.843 \\
$\rho^{\mathrm{H}}$ & 0.831 & 0.836 & 0.839 & 0.840 & \\
\hline
\end{tabular}

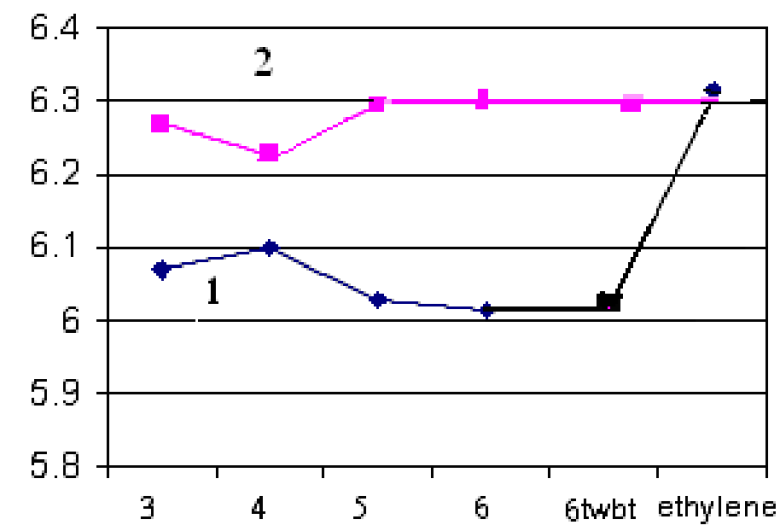

Fig. 4. Calculated total electron densities, $\rho^{\text {tot }}$, for [3]- to [6]radialene; $1-\rho_{\text {ring }}^{\text {tot }} ; 2-\rho_{\text {ext }}^{\text {tot }}$.

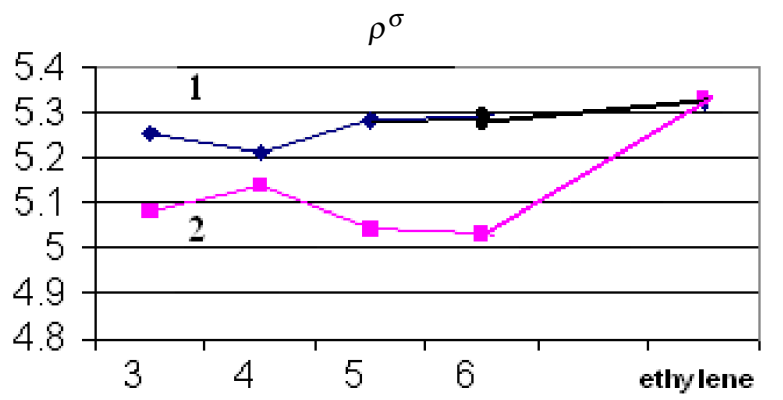

Fig. 5. Calculated $\sigma$ electron densities, $\rho^{\sigma}$, for [3]- to [6]radialene; $1-\rho_{\text {ext }}^{\sigma} ; 2-\rho_{\text {ring }}^{\sigma}$.

and $75 \mathrm{~cm}^{-1}\left(\Delta v_{\mathrm{C}-\mathrm{C}}\right)$. The change of the $\mathrm{A}_{1 \mathrm{~g}}\left(v_{\mathrm{C}-\mathrm{H}}\right)$ vibration runs in the opposite direction to that of $\mathrm{A}_{1 \mathrm{~g}}$ $\left(v_{\mathrm{CC}}\right)$. The decrease in the $v_{\mathrm{C}=\mathrm{C}}$ and $v_{\mathrm{C}-\mathrm{C}}$ values at a definite stage of transition, $[n]-$ to $[n+1]$-radialene, is encountered by an increase in the $v_{\mathrm{C}-\mathrm{H}}$ frequency at the same stage. It is noticed too, that the $\mathrm{A}_{1 \mathrm{~g}}\left(v_{\mathrm{C}-\mathrm{H}}\right)$ frequency decreases on going from ethylene to [3]radialene. Further increase in the radialene ring number causes an increase in the vibration frequency of $\mathrm{A}_{1 \mathrm{~g}}\left(v_{\mathrm{C}-\mathrm{H}}\right)$, as the change proceeds towards the carbon atom of the normal $\mathrm{C}=\mathrm{C}$ bond in the chair form [6]-radialene.

Distinguishing between the ring carbon atoms, $\mathrm{C}_{\text {ring }}$, and the external carbon atoms, $\mathrm{C}_{\mathrm{ext}}$, and con-

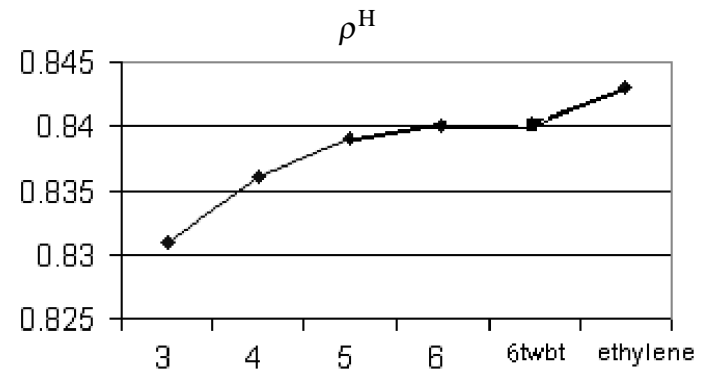

Fig. 6. Calculated change in electron densities at the $\mathrm{H}$ atoms, $\rho^{\mathrm{H}}$, due to the change of the radialene ring size.

sidering the calculated total electron densities $\left(\rho^{\sigma}+\right.$ $\rho^{\pi}$ ) for each carbon atom, one finds that for all considered radialenes the values are smaller than that calculated for ethylene (Table 3, Fig. 4).

Figure 5 shows the calculated $\sigma$ electron densities $\left(\rho^{\sigma}\right)$ for [3]- to [6]-radialene. In a similar manner to that of the total electron density, the $\sigma$ electron densities at the carbon atoms, both $\rho_{\text {ring }}^{\sigma}$ and $\rho_{\text {ext }}^{\sigma}$, show smaller values than that of ethylene too, the $\rho_{\text {ring }}^{\sigma}$ values being smaller than those of $\rho_{\text {ext }}^{\sigma}$. No $\rho^{\sigma}$ value is reported for the twist boat [6]-radialene due to the nonunified direction of its $\pi$-bonds.

Figure 6 shows the calculated change in electron densities at the hydrogen atoms, $\rho^{\mathrm{H}}$, due to the change in the radialene ring size. The figure shows a slight but gradual increase in the $\rho^{\mathrm{H}}$ values on going from [3]- to [6]-radialene.

As stated in the previous paragraph it is found that the densities at the ring carbon atoms, $\mathrm{C}_{\text {ring }}$, are smaller than those at the external carbon atoms, $\mathrm{C}_{\text {ext }}$. This seems to contradict our assumption of an sp hybridization at the ring atoms, which should possess higher electron affinities than expected. Two factors might explain this result:

1. the delocalization of the ring electrons, causing a partial distribution of the electrons in the bond regions besides the localization at the $\mathrm{C}$ atoms, since a Mulliken population analysis was drawn to describe the electron distribution in the molecule; 
2. for the $\mathrm{C}_{\text {ext }}$ atoms a partial shift of electrons exists from the neighbored $\mathrm{H}$ atoms to $\mathrm{C}$, as might be viewed considering the calculated electron densities at the $\mathrm{H}$ atoms (Table 3).

Trying to correlate the calculated $\mathrm{A}_{1 \mathrm{~g}}\left(v_{\mathrm{C}-\mathrm{H}}\right)$ frequencies with each of the two types of the $\mathrm{C}$ electron densities, $\rho_{\text {ext }}^{\sigma}$ or $\rho_{\text {ext }}^{\text {total }}$, no significant correlation was obtained. However sufficient correlation with the $\rho^{\mathrm{H}}$ values is expected, as might be concluded on comparing the shapes of the curves in Figs. 2 and 6. The

[1] H. Hopf and A. K. Wick, Helv. Chim. Acta 44, 380 (1961); G. W. Griffin and L. I. Petersen, J. Am. Chem. Soc. 84, 3398 (1962); H. D. Harzler, J. Am. Chem. Soc. 88, 3166 (1966); F. P. van Remoortere and F. P. Boer, J. Am. Chem. Soc. 92, 3355 (1970); T. Inoue, T. Kaneda, and S. Misumi, Tetrahedron Lett. 15, 2969 (1974); P. J. Stang and T. E. Fisk, J. Am. Chem. Soc. 101, 4772 (1979); P. J. Stang and T.E. Fisk, J. Am. Chem. Soc. 102, 6813 (1980); L. Trabert and H. Hopf, Ann. Chem., 1786 (1980); K. Tanaka and F. Toda, Tetrahedron Lett. 21, 2713 (1980); K. Hagenbruch, K. Hesse, S. Hünig, and G. Klug, Ann. Chem., 256 (1981); H. Hart, D. L. Ward, K. Tanaka, and F. Toda, Tetrahedron Lett. 23, 2125 (1982); M. Iyoda, H. Otani, M. Oda, Y. Kai, Y. Baba, and N. Kasai, J. Am. Chem. Soc. 108, 5371 (1986); G. Maas, and H. Hopf, in: The Chemistry of Functional Groups, Vol. 1, The Chemistry of Dienes and Polyenes (Eds. S. Patai and Z. Rappoport), John Wiley and Sons Ltd., Chichester 1997, p. 927; J. Benet-Cuchholz, R. Boese, T. Haumann, and M. Trattenberg, in: The Chemistry of Functional Groups, Vol. 1, The Chemistry of Dienes and Polyenes, (Eds. S. Patai and Z. Rappoport), John Wiley and Sons Ltd., Chichester 1997, p. 25.

[2] R. M. Kubba, Z. Naturforsch. 56a, 505 (2001); R. M. Kubba, S. H. Rida, and A. H. Hanoon, Z. Naturforsch. 60a, 419 (2005).

[3] Th. Förster, Z. Physik. Chem. B 43, 58 (1939).

[4] C. A. Coulson and W.E. Moffitt, J. Chem. Phys. 15, 151 (1947)

[5] A. D. Walsh, Nature (London) 159, 167 (1947). frequency value for ethylene seems to be out of the correlation scheme, obviously due to clustering of the $\mathrm{CH}_{2}$ groups in radialenes and the solo motion of the same group in ethylene.

\section{Acknowledgement}

This work was done applying the Gaussian03 (J. Pople et al.) and Molek9000 (P. Bischof, Heidelberg) computer programs. M. Shanshal thanks Prof. R. Gleiter, Heidelberg, for providing the computation facilities.

[6] R. Gleiter, Top. Curr. Chem. 86, 197 (1979); M. Shanshal, Z. Naturforsch. 27a, 1665 (1972).

[7] E. Heilbronner, Theor. Chim. Acta 4, 64 (1966),

[8] E. Weltin, F. Gerson, J. N. Murell, and E. Heilbronner, Helv. Chim. Acta 44, 1400 (1961).

[9] C. Lee, W. Yang, and R. G. Parr, Phys. Rev. B 37, 785 (1988); A. D. Becke, Phys. Rev. A 38, 3098 (1988); B. Miehlich, A. Savin, H. Stoll, and H. Preuss, Chem. Phys. Lett. 157, 200 (1989); A. D. Becke, J. Chem. Phys. 98, 5648 (1993).

[10] See Gaussian 98 user's manual and references therein, Gaussian Inc. Carnegie Office Park, Bldg. 6, Carnegie, PA 15106, U.S.A., p. 25.

[11] L. S. Bartlett, E. A. Roth, C. D. Hollmell, K. Kuchitsu, and J. E. Young, Jr., Chem. Phys. 42, 2683 (1965); see also: Tables of Interatomic Distances (Ed. L.E. Sutton), Chem. Soc. Spec. Publ. No. 11 (1958) and No. 18 (1965).

[12] E. A. Dorko, J.L. Hencher, and S. H. Bauer, Tetrahedron 24, 2455 (1968).

[13] S. Hashmi, K. Polborn, and G. Szeimies, Chem. Ber. 122, 2399 (1989).

[14] W. March and J. K. Dunitz, Helv. Chim. Acta 58, 707 (1975).

[15] K. H. Rhee and F. A. Miller, Spectrochim. Acta 27A, 1 (1971).

[16] F. A. Miller, F. R. Brown, and K. A. Rhee, Spectrochim. Acta 28A, 1467 (1971).

[17] H. Hopf and G. Maas, Angew. Chem. Int. Ed. 31, 931 (1992).

[18] J. L. Duncan, D.C. McKean, and P.D. Mallinson, J. Mol. Struct. 45, 221 (1973). 